\title{
A Coupled Fixed Point Theorem for Mixed Monotone Map- pings on Partial Ordered G-Metric Spaces
}

\section{Hosoo LeE}

College of Basic Studies, Yeungnam University, 280 Daehak-Ro, Gyengsan Gyengbook, 712-749 Korea

e-mail : hosoo@yu.ac.kr

ABstract. In this paper, we establish coupled fixed point theorems for mixed monotone mappings satisfying nonlinear contraction involving a pair of altering distance functions in ordered $G$-metric spaces. Via presented theorems we extend and generalize the results of Harjani et al. [J. Harjani, B. López and K. Sadarangani, Fixed point theorems for mixed monotone operators and applications to integral equations, Nonlinear Anal. 74 (2011) 1749-1760] and Choudhury and Maity [B.S. Choudhury and P. Maity, Coupled fixed point results in generalized metric spaces. Math. Comput. Model. 54 (2011), 73-79].

\section{Introduction and Preliminaries}

Mustafa and Sims [21] introduced the notion of $G$-metric spaces. The structure of $G$-metric spaces is a generalization of metric spaces. Mustafa and Sims [21] initiated the theory of fixed points in $G$-metric spaces and established the Banach contraction principle in this generalized structure. Afterwards, different authors proved several fixed point results in this space (see, e.g., $[2,3,6,7,10,11,18,19$, $20,22,27,28])$.

Definition 1.1.([21]) Let $X$ be a nonempty set. Suppose that a mapping $G$ : $X \times X \times X \rightarrow \mathbb{R}_{+}=[0, \infty)$ satisfies:

(G1) $G(x, y, z)=0$ if $x=y=z$;

(G2) $G(x, x, y)>0$ for all $x, y \in X$ with $x \neq y$;

(G3) $G(x, x, y) \leq G(x, y, z)$ for all $x, y, z \in X$ with $z \neq y$;

(G4) (symmetry in all three variables)

$$
G(x, y, z)=G(x, z, y)=G(y, z, x)=\ldots, ;
$$

(G5) (rectangle inequality)

$$
G(x, y, z) \leq G(x, a, a)+G(a, y, z) \text { for all } x, y, z, a \in X .
$$

Then $G$ is called a $G$-metric on $X$ and $(X, G)$ is called a $G$-metric space or a generalized metric space by $G$.

Received October 15, 2013; accepted December 13, 2013.

2010 Mathematics Subject Classification: 47H10, 54H25.

Key words and phrases: Fixed point, mixed monotone property, $G$-metric space. 
The following are examples of $G$-metric spaces.

Example 1.2. Let $(\mathbb{R}, d)$ be the usual metric space. Define $G_{1}$ and $G_{2}$ by

$$
\begin{gathered}
G_{1}(x, y, z)=d(x, y)+d(y, z)+d(x, z), \\
G_{2}(x, y, z)=\max \{d(x, y), d(y, z), d(x, z)\}
\end{gathered}
$$

for all $x, y, z \in \mathbb{R}$. Then it is clear that $\left(\mathbb{R}, G_{1}\right)$ and $\left(\mathbb{R}, G_{2}\right)$ are $G$-metric spaces.

Example 1.3. Let $X=\{a, b\}$ and $G: X \times X \times X \rightarrow[0, \infty)$ be defined by

$$
\begin{gathered}
G(a, a, a)=G(b, b, b)=0, \\
G(a, a, b)=G(a, b, a)=G(b, a, a)=1, \\
G(a, b, b)=G(b, a, b)=G(b, b, a)=2 .
\end{gathered}
$$

It is easy to show that the function $G$ satisfies all properties of Definition .

Definition 1.4.([21]) Let $X$ be a $G$-metric space and let $\left\{x_{n}\right\}$ be a sequence of points of $X$. A point $x \in X$ is said to be the limit of a sequence $\left\{x_{n}\right\}$ if $\lim _{n, m \rightarrow \infty} G\left(x, x_{n}, x_{m}\right)=0$ and we say in this case that the sequence $\left\{x_{n}\right\}$ is said to be $G$-convergent to $x$.

Thus, $x_{n} \rightarrow x$ in a $G$-metric space $X$ if for any $\epsilon>0$, there exists a positive integer $N$ such that $G\left(x, x_{n}, x_{m}\right)<\epsilon$, for all $n, m \geq N$. It has been shown in [21] that the $G$-metric induces a Hausdorff topology and the convergence described in the above definition is relative to this topology.

Lemma 1.5.([21]) If $X$ is a $G$-metric space, then the following are equivalent:

(i) $\left\{x_{n}\right\}$ is $G$-convergent to $x$,

(ii) $G\left(x_{n}, x_{n}, x\right) \rightarrow 0$ as $n \rightarrow \infty$

(iii) $G\left(x_{n}, x, x\right) \rightarrow 0$ as $n \rightarrow \infty$.

Definition 1.6. ([21]) Let $X$ be a $G$-metric space, a sequence $\left\{x_{n}\right\}$ is called $G$ Cauchy if for every $\epsilon>0$ there is a positive integer $N$ such that $G\left(x_{n}, x_{m}, x_{l}\right)<\epsilon$ for all $n, m, l \geq N$, that is, if $G\left(x_{n}, x_{m}, x_{l}\right) \rightarrow 0$, as $n, m, l \rightarrow \infty$.

Lemma 1.7.[[21]] If $X$ is a $G$-metric space, then the following are equivalent:

(i) The sequence $\left\{x_{n}\right\}$ is $G$-Cauchy.

(ii) For every $\epsilon>0$, there exists a positive integer $N$ such that

$$
G\left(x_{n}, x_{m}, x_{m}\right)<\epsilon \text { for all } n, m \geq N \text {. }
$$

Definition 1.8.([21]) A $G$-metric space $X$ is said to be $G$-complete (or a complete $G$-metric space) if every $G$-Cauchy sequence is $G$-convergent in $(X, G)$.

Definition 1.9.([21]) Let $(X, G)$ and $\left(X^{\prime}, G^{\prime}\right)$ be two generalized metric spaces. A mapping $f: X \rightarrow X^{\prime}$ is $G$-continuous at a point $x \in X$ if and only if it is $G$ sequentially continuous at $x$, that is, whenever $\left\{x_{n}\right\}$ is $G$-convergent to $x,\left\{f\left(x_{n}\right)\right\}$ is $G^{\prime}$-convergent to $f(x)$. 
Definition 1.10.([21]) Let $X$ be a $G$-metric space. A mapping $F: X \times X \rightarrow X$ is said to be continuous if for any two $G$-convergent sequences $\left\{x_{n}\right\}$ and $\left\{y_{n}\right\}$ converging to $x$ and $y$, respectively, $\left\{F\left(x_{n}, y_{n}\right)\right\}$ is $G$-convergent to $F(x, y)$.

In recent years, there has been a lot of interest in establishing fixed point theorems on ordered metric spaces with a contractive condition which holds for all points that are related by partial ordering. This trend was initiated by Ran and Reurings in [26] where they extended the Banach contraction principle in partially ordered sets with some applications to matrix equations. Subsequently, Nieto and Rodríguez-López [24] extended the results in [26] for non-decreasing mappings and applied them to obtain a unique solution for a first-order ordinary differential equation with periodic boundary conditions. Recently, many researchers have obtained common fixed point results on partially ordered metric spaces (see, e.g., $[4,5,8,9,14,23,24,25])$.

Bhaskar and Lakshmikantham [12] introduced the notions of a mixed monotone mapping and a coupled fixed point, and proved some coupled fixed point theorems for mixed mappings in ordered metric spaces. Afterwards, Lakshmikantham and Ćirić [16] have established coupled coincidence and coupled fixed point theorems for two mappings $F$ and $g$, where $F$ has the mixed $g$-monotone property. Many other results on coupled fixed point theory exist in the literatures [1, 13, 16, 17, 29, 30].

Definition 1.11.([12]) Let $(X, \leq)$ be a partial ordered set. A mapping $F: X \times X \rightarrow$ $X$ is said to have the a mixed monotone property if $F$ is monotone nondecreasing in its first argument and is monotone nonincreasing in its second argument, that is, for any $x, y \in X$

$$
x_{1}, x_{2} \in X, x_{1} \leq x_{2} \Rightarrow F\left(x_{1}, y\right) \leq F\left(x_{2}, y\right)
$$

and

$$
y_{1}, y_{2} \in X, y_{1} \leq y_{2} \Rightarrow F\left(x, y_{1}\right) \geq F\left(x, y_{2}\right) .
$$

Definition 1.12.([12]) An element $(x, y) \in X \times X$ is called a coupled fixed point of mapping $F: X \times X \rightarrow X$ if

$$
x=F(x, y) \text { and } y=F(y, x) .
$$

An altering distance function was introduced by Khan et al. in [15] where they present some fixed point theorems.

Definition 1.13. An altering distance function is a map $\Psi:[0, \infty) \rightarrow[0, \infty)$ satisfying:

(i) $\Psi$ is continuous and nondecreasing;

(ii) $\Psi(t)=0$ if and only if $t=0$. 
Let $(X, \leq)$ be a partially ordered set and suppose that there exists a metric $d$ on $X$ such that $(X, d)$ is a complete metric space. Harjani, López and Sadarangani [13] established some coupled fixed point theorems for the mixed monotone mapping $F: X \times X \rightarrow X$ involving a pair of altering distance functions under a contractive condition of the form

$$
\phi(d(F(x, y), F(u, v))) \leq \phi(\max \{d(x, u), d(y, v)\})-\psi(\max \{d(x, u), d(y, v)\})
$$

for $x, y, u, v \in X$ with $x \geq u$ and $y \leq v$, where $\phi$ and $\psi$ are altering distance functions. The purpose of this work is to extend this theorem to the set of $G$-metric spaces.

\section{Coupled Fixed Point in $G$-Metric Spaces}

Theorem 2.1. Let $(X, \leq)$ be a partially ordered set such that there exists a complete $G$-metric on $X$ and $F: X \times X \rightarrow X$ be a continuous mapping having the mixed monotone property. Suppose that there exist altering distance functions $\varphi$ and $\psi$ such that

$$
\begin{aligned}
& \varphi(G(F(x, y), F(u, v), F(w, z))) \\
& \leq \varphi(\max \{G(x, u, w), G(y, v, z)\})-\psi(\max \{G(x, u, w), G(y, v, z)\})
\end{aligned}
$$

for all $x, y, z, u, v, w \in X$ for which $x \geq u \geq w$ and $y \leq v \leq z$ where either $x \neq u$ or $y \neq v$. If there exist $x_{0}, y_{0} \in X$ such that

$$
x_{0} \leq F\left(x_{0}, y_{0}\right) \quad \text { and } \quad y_{0} \geq F\left(y_{0}, x_{0}\right),
$$

then $F$ has a coupled fixed point.

Proof. We construct sequences $\left(x_{n}\right)$ and $\left(y_{n}\right)$ putting

$$
x_{n+1}=F\left(x_{n}, y_{n}\right) \text { and } y_{n+1}=F\left(y_{n}, x_{n}\right) \text { for } n \geq 0 .
$$

In order that the proof is more comprehensive, we will divide it in several steps.

Step 1. $x_{n} \leq x_{n+1}$ and $y_{n} \geq y_{n+1}$, for $n \geq 0$.

In fact, we use mathematical induction.

As $x_{0} \leq F\left(x_{0}, y_{0}\right)=x_{1}$ and $y_{0} \geq F\left(y_{0}, x_{0}\right)=y_{1}$ our claim is satisfied for $n=0$.

Again by the induction hypothesis and the mixed monotone property of $F$, we have

$$
x_{n+1}=F\left(x_{n}, y_{n}\right) \geq F\left(x_{n-1}, y_{n-1}\right)=x_{n}
$$

and

$$
y_{n+1}=F\left(y_{n}, x_{n}\right) \leq F\left(y_{n-1}, x_{n-1}\right)=y_{n} .
$$

This proves our claim.

Step 2. $\lim _{n \rightarrow \infty} G\left(x_{n}, x_{n+1}, x_{n+1}\right)=\lim _{n \rightarrow \infty} G\left(y_{n}, y_{n+1}, y_{n+1}\right)=0$. 
From the contractive condition (2.1) and Step 1, we obtain

$$
\begin{aligned}
& \varphi\left(G\left(x_{n}, x_{n+1}, x_{n+1}\right)\right) \\
& =\varphi\left(G\left(F\left(x_{n-1}, y_{n-1}\right), F\left(x_{n}, y_{n}\right), F\left(x_{n}, y_{n}\right)\right)\right) \\
& \leq \varphi\left(\max \left\{G\left(x_{n-1}, x_{n}, x_{n}\right), G\left(y_{n-1}, y_{n}, y_{n}\right)\right\}\right) \\
& \quad-\psi\left(\max \left\{G\left(x_{n-1}, x_{n}, x_{n}\right), G\left(y_{n-1}, y_{n}, y_{n}\right)\right\}\right) \\
& \leq \varphi\left(\max \left\{G\left(x_{n-1}, x_{n}, x_{n}\right), G\left(y_{n-1}, y_{n}, y_{n}\right)\right\}\right) .
\end{aligned}
$$

Using the fact that $\varphi$ is nondecreasing, we have

$$
G\left(x_{n}, x_{n+1}, x_{n+1}\right) \leq \max \left\{G\left(x_{n-1}, x_{n}, x_{n}\right), G\left(y_{n-1}, y_{n}, y_{n}\right)\right\} .
$$

Similarly, we get

$$
G\left(y_{n}, y_{n+1}, y_{n+1}\right) \leq \max \left\{G\left(x_{n-1}, x_{n}, x_{n}\right), G\left(y_{n-1}, y_{n}, y_{n}\right)\right\} .
$$

Hence, the sequence $\left\{\max \left\{G\left(x_{n}, x_{n+1}, x_{n+1}\right), G\left(y_{n}, y_{n+1}, y_{n+1}\right)\right\}\right\}_{n=0}^{\infty}$ is nonnegative and decreasing. This implies that there exists $\alpha \geq 0$ such that

$$
\lim _{n \rightarrow \infty} \max \left\{G\left(x_{n}, x_{n+1}, x_{n+1}\right), G\left(y_{n}, y_{n+1}, y_{n+1}\right)\right\}=\alpha .
$$

It is easily seen that if $\varphi:[0, \infty) \rightarrow[0, \infty)$ is nondecreasing, $\varphi\left(\max \left\{a_{1}, a_{2}\right\}\right)=$ $\max \left\{\varphi\left(a_{1}\right), \varphi\left(a_{2}\right)\right\}$ for $a_{1}, a_{2} \in[0, \infty)$. Taking into account this and $(2.2)$ we get

$$
\begin{aligned}
& \varphi\left(\max \left\{G\left(x_{n}, x_{n+1}, x_{n+1}\right), G\left(y_{n}, y_{n+1}, y_{n+1}\right)\right\}\right) \\
& =\max \left\{\varphi\left(G\left(x_{n}, x_{n+1}, x_{n+1}\right)\right), \varphi\left(G\left(y_{n}, y_{n+1}, y_{n+1}\right)\right)\right\} \\
& \leq \varphi\left(\max \left\{G\left(x_{n-1}, x_{n}, x_{n}\right), G\left(y_{n-1}, y_{n}, y_{n}\right)\right\}\right) \\
& \quad-\psi\left(\max \left\{G\left(x_{n-1}, x_{n}, x_{n}\right), G\left(y_{n-1}, y_{n}, y_{n}\right)\right\}\right) \\
& \leq \varphi\left(\max \left\{G\left(x_{n-1}, x_{n}, x_{n}\right), G\left(y_{n-1}, y_{n}, y_{n}\right)\right\}\right) .
\end{aligned}
$$

Since $\varphi$ is a continuous function, letting $n \rightarrow \infty$ in the above inequalities yields

$$
\varphi(\alpha) \leq \varphi(\alpha)-\psi(\alpha) \leq \varphi(\alpha) .
$$

and this implies $\psi(\alpha)=0$. Since $\psi$ is an altering distance function, $\alpha=0$ and

$$
\lim _{n \rightarrow \infty} \max \left\{G\left(x_{n}, x_{n+1}, x_{n+1}\right), G\left(y_{n}, y_{n+1}, y_{n+1}\right)\right\}=0,
$$

and this proves our claim.

Step 3. $\left\{x_{n}\right\}$ and $\left\{y_{n}\right\}$ are $G$-Cauchy sequences.

Assume that at least one of the sequences $\left\{x_{n}\right\}$ and $\left\{y_{n}\right\}$ is not a $G$-Cauchy sequence. By Lemma, this implies that

$$
\lim _{n, m \rightarrow \infty} G\left(x_{n}, x_{m}, x_{m}\right) \neq 0 \quad \text { or } \quad \lim _{n, m \rightarrow \infty} G\left(y_{n}, y_{m}, y_{m}\right) \neq 0
$$

and, consequently,

$$
\lim _{n, m \rightarrow \infty} \max \left\{G\left(x_{n}, x_{m}, x_{m}\right), G\left(y_{n}, y_{m}, y_{m}\right)\right\} \neq 0 .
$$


This means that there exists an $\varepsilon>0$ for which we can find two subsequences $\left\{x_{m(k)}\right\}$ and $\left\{x_{n(k)}\right\}$ of $\left\{x_{k}\right\}$ such that $n(k)$ is the smallest index for which

$$
\max \left\{G\left(x_{n(k)}, x_{m(k)}, x_{m(k)}\right), G\left(y_{n(k)}, y_{m(k)}, y_{m(k)}\right)\right\} \geq \varepsilon
$$

for $n(k)>m(k)>k$.

This means that

$$
\max \left\{G\left(x_{n(k)-1}, x_{m(k)}, x_{m(k)}\right), G\left(y_{n(k)-1}, y_{m(k)}, y_{m(k)}\right)\right\}<\varepsilon .
$$

The rectangle inequality and (2.4) give us, for each $k$,

$$
\begin{aligned}
& G\left(x_{n(k)}, x_{m(k)}, x_{m(k)}\right) \\
& \leq G\left(x_{n(k)}, x_{n(k)-1}, x_{n(k)-1}\right)+G\left(x_{n(k)-1}, x_{m(k)}, x_{m(k)}\right) \\
& <G\left(x_{n(k)}, x_{n(k)-1}, x_{n(k)-1}\right)+\varepsilon
\end{aligned}
$$

and

$$
\begin{aligned}
& G\left(y_{n(k)}, y_{m(k)}, y_{m(k)}\right) \\
& \leq G\left(y_{n(k)}, y_{n(k)-1}, y_{n(k)-1}\right)+G\left(y_{n(k)-1}, y_{m(k)}, y_{m(k)}\right) \\
& <G\left(y_{n(k)}, y_{n(k)-1}, y_{n(k)-1}\right)+\varepsilon
\end{aligned}
$$

Using (2.3), (2.5) and (2.6), we get

$$
\begin{aligned}
\varepsilon & \leq \max \left\{G\left(x_{n(k)}, x_{m(k)}, x_{m(k)}\right), G\left(y_{n(k)}, y_{m(k)}, y_{m(k)}\right)\right\} \\
& <\max \left\{G\left(x_{n(k)}, x_{n(k)-1}, x_{n(k)-1}\right), G\left(y_{n(k)}, y_{n(k)-1}, y_{n(k)-1}\right)\right\}+\varepsilon .
\end{aligned}
$$

Letting $k \rightarrow \infty$ in the last inequality and using Step 2, we obtain that

$$
\lim _{k \rightarrow \infty} \max \left\{G\left(x_{n(k)}, x_{m(k)}, x_{m(k)}\right), G\left(y_{n(k)}, y_{m(k)}, y_{m(k)}\right)\right\}=\varepsilon .
$$

Again, the rectangle inequality and (2.4) give us, for each $k$,

$$
\begin{aligned}
& G\left(x_{n(k)-1}, x_{m(k)-1}, x_{m(k)-1}\right) \\
& \leq G\left(x_{n(k)-1}, x_{m(k)}, x_{m(k)}\right)+G\left(x_{m(k)}, x_{m(k)-1}, x_{m(k)-1}\right) \\
& <\varepsilon+G\left(x_{m(k)}, x_{m(k)-1}, x_{m(k)-1}\right)
\end{aligned}
$$

and

$$
\begin{aligned}
& G\left(y_{n(k)-1}, y_{m(k)-1}, y_{m(k)-1}\right) \\
& \leq G\left(y_{n(k)-1}, y_{m(k)}, y_{m(k)}\right)+G\left(y_{m(k)}, y_{m(k)-1}, y_{m(k)-1}\right) \\
& <\varepsilon+G\left(y_{m(k)}, y_{m(k)-1}, y_{m(k)-1}\right) .
\end{aligned}
$$

By (2.8) and (2.9) we get

$$
\begin{aligned}
& \max \left\{G\left(x_{n(k)-1}, x_{m(k)-1}, x_{m(k)-1}\right), G\left(y_{n(k)-1}, y_{m(k)-1}, y_{m(k)-1}\right)\right\} \\
& <\max \left\{G\left(x_{m(k)}, x_{m(k)-1}, x_{m(k)-1}\right), G\left(y_{m(k)}, y_{m(k)-1}, y_{m(k)-1}\right)\right\}+\varepsilon .
\end{aligned}
$$


Using the rectangle inequality we have

$$
\begin{aligned}
& G\left(x_{n(k)}, x_{m(k)}, x_{m(k)}\right) \\
& \leq G\left(x_{n(k)}, x_{n(k)-1}, x_{n(k)-1}\right)+G\left(x_{n(k)-1}, x_{m(k)-1}, x_{m(k)-1}\right) \\
& \quad+G\left(x_{m(k)-1}, x_{m(k)}, x_{m(k)}\right)
\end{aligned}
$$

and

$$
\begin{aligned}
& G\left(y_{n(k)}, y_{m(k)}, y_{m(k)}\right) \\
\leq \quad & G\left(y_{n(k)}, y_{n(k)-1}, y_{n(k)-1}\right)+G\left(y_{n(k)-1}, y_{m(k)-1}, y_{m(k)-1}\right) \\
& +G\left(y_{m(k)-1}, y_{m(k)}, y_{m(k)}\right) .
\end{aligned}
$$

By the two last inequalities and (2.3) we get

$$
\begin{aligned}
\varepsilon & \leq \max \left\{G\left(x_{n(k)}, x_{m(k)}, x_{m(k)}\right), G\left(y_{n(k)}, y_{m(k)}, y_{m(k)}\right)\right\} \\
& \leq \max \left\{G\left(x_{n(k)}, x_{n(k)-1}, x_{n(k)-1}\right), G\left(y_{n(k)}, y_{n(k)-1}, y_{n(k)-1}\right)\right\} \\
& +\max \left\{G\left(x_{n(k)-1}, x_{m(k)-1}, x_{m(k)-1}\right), G\left(y_{n(k)-1}, y_{m(k)-1}, y_{m(k)-1}\right)\right\} \\
& +\max \left\{G\left(x_{m(k)-1}, x_{m(k)}, x_{m(k)}\right), G\left(y_{m(k)-1}, y_{m(k)}, y_{m(k)}\right)\right\} .
\end{aligned}
$$

By (2.10) and (2.11) we have

$$
\begin{aligned}
\varepsilon+ & \max \left\{G\left(x_{m(k)}, x_{m(k)-1}, x_{m(k)-1}\right), G\left(y_{m(k)}, y_{m(k)-1}, y_{m(k)-1}\right)\right\} \\
> & \max \left\{G\left(x_{n(k)-1}, x_{m(k)-1}, x_{m(k)-1}\right), G\left(y_{n(k)-1}, y_{m(k)-1}, y_{m(k)-1}\right)\right\} \\
\geq & \varepsilon-\max \left\{G\left(x_{n(k)}, x_{n(k)-1}, x_{n(k)-1}\right), G\left(y_{n(k)}, y_{n(k)-1}, y_{n(k)-1}\right)\right\} \\
& -\max \left\{G\left(x_{m(k)-1}, x_{m(k)}, x_{m(k)}\right), G\left(y_{m(k)-1}, y_{m(k)}, y_{m(k)}\right)\right\} .
\end{aligned}
$$

Letting $k \rightarrow \infty$ in the last inequality, and by Step 2, we obtain that

$$
\max \left\{G\left(x_{n(k)-1}, x_{m(k)-1}, x_{m(k)-1}\right), G\left(y_{n(k)-1}, y_{m(k)-1}, y_{m(k)-1}\right)\right\}=\varepsilon .
$$

Since $n(k)>m(k)>k$, by Step 1

$$
x_{n(k)-1} \leq x_{n(k)} \text { and } y_{n(k)-1} \geq y_{n(k)}
$$

and using the contractive condition we can obtain

$$
\begin{aligned}
& \varphi\left(G\left(x_{n(k)}, x_{m(k)}, x_{m(k)}\right)\right) \\
& =\varphi\left(G\left(F\left(x_{n(k)-1}, y_{n(k)-1}\right), F\left(x_{m(k)-1}, y_{m(k)-1}\right), F\left(x_{m(k)-1}, y_{m(k)-1}\right)\right)\right) \\
& \leq \varphi\left(\max \left\{G\left(x_{n(k)-1}, x_{m(k)-1}, x_{m(k)-1}\right), G\left(y_{n(k)-1}, y_{m(k)-1}, y_{m(k)-1}\right)\right\}\right) \\
& \quad-\psi\left(\max \left\{G\left(x_{n(k)-1}, x_{m(k)-1}, x_{m(k)-1}\right), G\left(y_{n(k)-1}, y_{m(k)-1}, y_{m(k)-1}\right)\right\}\right)
\end{aligned}
$$

and

$$
\begin{aligned}
& \varphi\left(G\left(y_{n(k)}, y_{m(k)}, y_{m(k)}\right)\right) \\
& =\varphi\left(G\left(F\left(y_{n(k)-1}, x_{n(k)-1}\right), F\left(y_{m(k)-1}, x_{m(k)-1}\right), F\left(y_{m(k)-1}, x_{m(k)-1}\right)\right)\right) \\
& \leq \varphi\left(\max \left\{G\left(x_{n(k)-1}, x_{m(k)-1}, x_{m(k)-1}\right), G\left(y_{n(k)-1}, y_{m(k)-1}, y_{m(k)-1}\right)\right\}\right) \\
& \quad-\psi\left(\max \left\{G\left(x_{n(k)-1}, x_{m(k)-1}, x_{m(k)-1}\right), G\left(y_{n(k)-1}, y_{m(k)-1}, y_{m(k)-1}\right)\right\}\right) .
\end{aligned}
$$


Thus,

$(2.13)$

$$
\begin{aligned}
& \varphi\left(\max \left\{G\left(x_{n(k)}, x_{m(k)}, x_{m(k)}\right), G\left(y_{n(k)}, y_{m(k)}, y_{m(k)}\right)\right\}\right) \\
& \leq \varphi\left(\max \left\{G\left(x_{n(k)-1}, x_{m(k)-1}, x_{m(k)-1}\right), G\left(y_{n(k)-1}, y_{m(k)-1}, y_{m(k)-1}\right)\right\}\right) \\
& -\psi\left(\max \left\{G\left(x_{n(k)-1}, x_{m(k)-1}, x_{m(k)-1}\right), G\left(y_{n(k)-1}, y_{m(k)-1}, y_{m(k)-1}\right)\right\}\right) .
\end{aligned}
$$

Finally, letting $k \rightarrow \infty$ in (2.13) and using (2.7), (2.12), and the continuity of $\varphi$ and $\psi$, we get

$$
\varphi(\varepsilon) \leq \varphi(\varepsilon)-\psi(\varepsilon)
$$

and, consequently, $\psi(\varepsilon)=0$. Since $\psi$ is an altering distance function, $\varepsilon=0$, and this is a contradiction. This proves our claim.

Since $(X, G)$ is a complete $G$-metric space there exist $x, y \in X$ such that the sequences $\left\{x_{k}\right\}$ and $\left\{y_{k}\right\}$ are $G$-convergent to $x$ and $y$, respectively.

In fact, using the continuity of $F$ we have

$$
\begin{aligned}
& x=\lim _{k \rightarrow \infty} x_{k+1}=\lim _{k \rightarrow \infty} F\left(x_{k}, y_{k}\right)=F\left(\lim _{k \rightarrow \infty} x_{k}, \lim _{k \rightarrow \infty} y_{k}\right)=F(x, y) \\
& y=\lim _{k \rightarrow \infty} y_{k+1}=\lim _{k \rightarrow \infty} F\left(y_{k}, x_{k}\right)=F\left(\lim _{k \rightarrow \infty} y_{k}, \lim _{k \rightarrow \infty} x_{k}\right)=F(y, x) .
\end{aligned}
$$

This proves that $(x, y)$ is a coupled fixed point $F$.

In the following result, the continuity of $F$ is not required.

Theorem 2.2. Let $(X, \leq)$ be a partially ordered set such that there exists a complete $G$-metric on $X$ and $F: X \times X \rightarrow X$ be a mapping having the mixed monotone property. Suppose that there exist altering distance functions $\varphi$ and $\psi$ such that

$$
\begin{aligned}
& G(F(x, y), F(u, v), F(w, z)) \\
& \leq \varphi(\max \{G(x, u, w), G(y, v, z)\})-\psi(\max \{G(x, u, w), G(y, v, z)\})
\end{aligned}
$$

for all $x, y, z, u, v, w \in X$ for which $x \geq u \geq w$ and $y \leq v \leq z$ where either $x \neq u$ or $y \neq v$. If there exists $x_{0}, y_{0} \in X$ such that

$$
x_{0} \leq F\left(x_{0}, y_{0}\right) \quad \text { and } \quad y_{0} \geq F\left(y_{0}, x_{0}\right)
$$

and $X$ has the following property:

(i) if a nondecreasing sequence $\left\{x_{n}\right\}$ is $G$-convergent to $x$, then $x_{n} \leq x$ for all $n \in N$,

(ii) if a nonincreasing sequence $\left\{y_{n}\right\}$ is $G$-convergent to $y$, then $y_{n} \geq y$ for all $n \in N$,

then $F$ has a coupled fixed point.

Proof. Following the proof of Theorem we only have to check that $(x, y)$ is a coupled fixed point of $F$. 
In fact, since $\left\{x_{n}\right\}$ is nondecreasing and $x_{n} \rightarrow x$, and $\left\{y_{n}\right\}$ is nonincreasing and $y_{n} \rightarrow y$, by our assumption, $x_{n} \leq x$ and $y_{n} \geq y$ for every $n \in N$.

Applying the contractive condition of altering distance functions $\varphi$ and $\psi$ we have

$$
\begin{aligned}
& \varphi\left(G\left(F(x, y), F\left(x_{n}, y_{n}\right), F\left(x_{n}, y_{n}\right)\right)\right) \\
\leq & \varphi\left(\max \left\{G\left(x, x_{n}, x_{n}\right) G\left(y, y_{n}, y_{n}\right)\right\}\right)-\psi\left(\max \left\{G\left(x, x_{n}, x_{n}\right) G\left(y, y_{n}, y_{n}\right)\right\}\right) \\
\leq & \varphi\left(\max \left\{G\left(x, x_{n}, x_{n}\right) G\left(y, y_{n}, y_{n}\right)\right\}\right) .
\end{aligned}
$$

and, since $\varphi$ is nondecreasing, we obtain

$$
G\left(F(x, y), F\left(x_{n}, y_{n}\right), F\left(x_{n}, y_{n}\right)\right) \leq \max \left\{G\left(x, x_{n}, x_{n}\right) G\left(y, y_{n}, y_{n}\right)\right\} .
$$

On the other hand, by the rectangle inequality and (2.15) we get

$$
\begin{aligned}
& G(x, F(x, y), F(x, y)) \\
\leq & G\left(x, x_{n+1}, x_{n+1}\right)+G\left(x_{n+1}, F(x, y), F(x, y)\right) \\
= & G\left(x, x_{n+1}, x_{n+1}\right)+G\left(F\left(x_{n}, y_{n}\right), F(x, y), F(x, y)\right) \\
\leq & G\left(x, x_{n+1}, x_{n+1}\right)+\max \left\{G\left(x_{n}, x, x\right), G\left(y_{n}, y, y\right)\right\} .
\end{aligned}
$$

Taking $n \rightarrow \infty$ in the last inequality, Lemma 1.3 yields

$$
G(x, F(x, y), F(x, y))=0
$$

and hence, $x=F(x, y)$.

Using a similar argument it can be proved that $y=F(y, x)$ and this finished the proof.

Now, we will show that many results can be deduced from our previously obtained results.

Corollary 2.3. If in Theorem 2.1 (resp. Theorem 2.3) we replace the contractive condition by

there exists $\alpha \in[0,1)$ such that

$$
G(F(x, y), F(u, v), F(w, z)) \leq \alpha \cdot \max \{G(x, u, w), G(y, v, z)\}
$$

for all $x \geq u \geq w$ and $y \leq v \leq z$ where either $x \neq u$ or $y \neq v$, then $F$ has a coupled fixed point of $F$.

Proof. Taking as $\varphi=$ identity and $\psi=(1-\alpha) \varphi$, we obtain the corollary.

Corollary 2.4. If in Theorem 2.1 (resp. Theorem 2.2) we replace the contractive condition by 
there exist $\delta_{1}, \delta_{2} \in[0,1)$ and $\delta_{1}+\delta_{2}<1$ such that

$$
G(F(x, y), F(u, v), F(w, z)) \leq \delta_{1} G(x, u, w)+\delta_{2} G(y, v, z)
$$

for all $x \geq u \geq w$ and $y \leq v \leq z$ where either $x \neq u$ or $y \neq v$,

then $F$ has a coupled fixed point of $F$.

Proof. We have

$$
\begin{aligned}
G(F(x, y), F(u, v), F(w, z)) & \leq \delta_{1} G(x, u, w)+\delta_{2} G(y, v, z) \\
& \leq\left(\delta_{1}+\delta_{2}\right) \max \{G(x, u, w), G(y, v, z)\} .
\end{aligned}
$$

Therefore, applying Corollary 2.3 we obtain the desired result.

Remark 2.5. Taking $\delta_{1}=\delta_{2}=\frac{k}{2}$ in Corollary 2.4, we can obtain Theorem 3.2 of Choudhury and Maity [10].

\section{Uniqueness of Coupled Fixed Point in $G$-Metric Spaces}

In this section, we consider some additional conditions to ensure the uniqueness of a coupled fixed point in the setting of partially ordered $G$-metric spaces. Furthermore, we study appropriate conditions to ensure that for a coupled fixed point $(x, y)$ we have $x=y$.

Notice that if $(X, \leq)$ is a partially ordered set, we endow the product space $X \times X$ with the partial order relation given by

$$
(u, v) \leq(x, y) \Leftrightarrow x \geq u \text { and } y \leq v .
$$

We say that two pairs $(x, y)$ and $(u, v)$ are comparable.

Theorem 3.1. In addition to the hypotheses of Theorem 2.1, suppose that, for every $(a, b),(c, d) \in X \times X$, there exists a pair $(u, v) \in X \times X$ such that $(u, v)$ is comparable to $(a, b)$ and $(c, d)$. Then $F$ has a unique coupled fixed point.

Proof. Suppose that $(x, y)$ and $(z, t)$ are coupled fixed point of $F$, that is, $x=$ $F(x, y), y=F(y, x), z=F(z, t)$ and $t=F(t, z)$.

Let $(u, v)$ be an element of $X \times X$ and comparable to $(x, y)$ and $(z, t)$. Suppose that $(x, y) \geq(u, v)$ (the proof is similar in other cases).

We construct the sequences $\left\{u_{n}\right\}$ and $\left\{v_{n}\right\}$ defined by

$$
u_{0}=u, \quad v_{0}=v, \quad u_{n+1}=F\left(u_{n}, v_{n}\right), \quad v_{n+1}=F\left(v_{n}, u_{n}\right) .
$$

We claim that $(x, y) \geq\left(u_{n}, v_{n}\right)$ for each $n \in N$.

We will use the induction.

For $n=0$, as $(x, y) \geq(u, v)$, this means $u_{0}=u \leq x$ and $v_{0}=v \geq y$ and, thus, $\left(u_{0}, v_{0}\right) \leq(x, y)$. 
Suppose that $(x, y) \geq\left(u_{n}, v_{n}\right)$ for some $n \in N$. Then using the mixed monotone property of $F$, we get

$$
\begin{aligned}
& u_{n+1}=F\left(u_{n}, v_{n}\right) \leq F(x, y)=x, \\
& v_{n+1}=F\left(v_{n}, u_{n}\right) \geq F(y, x)=y
\end{aligned}
$$

and this proves our claim.

Since $(x, y) \geq\left(u_{n}, v_{n}\right)$, using the contractive condition we have

$$
\begin{aligned}
& \varphi\left(G\left(x, u_{n+1}, u_{n+1}\right)\right) \\
& =\varphi\left(G\left(F(x, y), F\left(u_{n}, v_{n}\right), F\left(u_{n}, v_{n}\right)\right)\right) \\
& \leq \varphi\left(\max \left\{G\left(x, u_{n}, u_{n}\right), G\left(y, v_{n}, v_{n}\right)\right\}\right)-\psi\left(\max \left\{G\left(x, u_{n}, u_{n}\right), G\left(y, v_{n}, v_{n}\right)\right\}\right) \\
& \leq \varphi\left(\max \left\{G\left(x, u_{n}, u_{n}\right), G\left(y, v_{n}, v_{n}\right)\right\}\right)
\end{aligned}
$$

and

$$
\begin{aligned}
& \varphi\left(G\left(y, v_{n+1}, v_{n+1}\right)\right) \\
& =\varphi\left(G\left(F(y, \bar{c}), F\left(v_{n}, n_{n}\right), F\left(v_{n}, u_{n}\right)\right)\right) \\
& \leq \varphi\left(\max \left\{G\left(x, u_{n}, u_{n}\right), G\left(y, v_{n}, v_{n}\right)\right\}\right)-\psi\left(\max \left\{G\left(x, u_{n}, u_{n}\right), G\left(y, v_{n}, v_{n}\right)\right\}\right) \\
& \leq \varphi\left(\max \left\{G\left(x, u_{n}, u_{n}\right), G\left(y, v_{n}, v_{n}\right)\right\}\right) .
\end{aligned}
$$

By the last two equation and using the fact that $\varphi$ is nondecreasing, we obtain

$$
\begin{aligned}
& \varphi\left(\max \left\{G\left(x, u_{n+1}, u_{n+1}\right), G\left(y, v_{n+1}, v_{n+1}\right)\right\}\right) \\
& =\max \left\{\varphi\left(G\left(x, u_{n+1}, u_{n+1}\right)\right), \varphi\left(G\left(y, v_{n+1}, v_{n+1}\right)\right)\right\} \\
& \leq \varphi\left(\max \left\{G\left(x, u_{n}, u_{n}\right), G\left(y, v_{n}, v_{n}\right)\right\}\right)-\psi\left(\max \left\{G\left(x, u_{n}, u_{n}\right), G\left(y, v_{n}, v_{n}\right)\right\}\right) \\
& \leq \varphi\left(\max \left\{G\left(x, u_{n}, u_{n}\right), G\left(y, v_{n}, v_{n}\right)\right\}\right) .
\end{aligned}
$$

This last inequality implies that

$$
\max \left\{G\left(x, u_{n+1}, u_{n+1}\right), G\left(y, v_{n+1}, v_{n+1}\right)\right\} \leq \max \left\{G\left(x, u_{n}, u_{n}\right), G\left(y, v_{n}, v_{n}\right)\right\} .
$$

Consequently, the sequence $\left(\max \left\{G\left(x, u_{n}, u_{n}\right), G\left(y, v_{n}, v_{n}\right)\right\}\right)$ is decreasing and nonnegative, and so, for certain $\alpha \geq 0$

$$
\lim _{n \rightarrow \infty} \max \left\{G\left(x, u_{n}, u_{n}\right), G\left(y, v_{n}, v_{n}\right)\right\}=\alpha .
$$

Letting $n \rightarrow \infty$ in (3.1) we have

$$
\varphi(\alpha) \leq \varphi(\alpha)-\psi(\alpha) \leq \varphi(\alpha)
$$

and this implies $\psi(\alpha)=0$ and, thus, $\alpha=0$.

Finally, as $\lim _{n \rightarrow \infty} \max \left\{G\left(x, u_{n}, u_{n}\right), G\left(y, v_{n}, v_{n}\right)\right\}=0$, this gives us that the sequences $\left\{u_{n}\right\}$ and $\left\{v_{n}\right\}$ are $G$-convergent to $x$ and $y$, respectively. This means that

$$
\begin{aligned}
& \lim _{n \rightarrow \infty} G\left(x, u_{n}, u_{n}\right)=\lim _{n \rightarrow \infty} G\left(x, x, u_{n}\right)=0 \\
& \lim _{n \rightarrow \infty} G\left(y, v_{n}, v_{n}\right)=\lim _{n \rightarrow \infty} G\left(y, y, v_{n}\right)=0 .
\end{aligned}
$$


Using a similar argument for a coupled fixed point $(z, t)$, we can obtain $\left\{u_{n}\right\}$ and $\left\{v_{n}\right\}$ are $G$-convergent to $z$ and $t$, respectively, that is,

$$
\begin{aligned}
& \lim _{n \rightarrow \infty} G\left(z, u_{n}, u_{n}\right)=\lim _{n \rightarrow \infty} G\left(z, z, u_{n}\right)=0, \\
& \lim _{n \rightarrow \infty} G\left(t, v_{n}, v_{n}\right)=\lim _{n \rightarrow \infty} G\left(t, t, v_{n}\right)=0 .
\end{aligned}
$$

By the rectangle inequality, for any $n \in N$, we have

$$
\begin{aligned}
& G(x, z, z) \leq G\left(x, u_{n}, u_{n}\right)+G\left(u_{n}, z, z\right), \\
& G(y, t, t) \leq G\left(y, v_{n}, v_{n}\right)+G\left(v_{n}, t, t\right)
\end{aligned}
$$

Letting $n \rightarrow \infty$ in the last inequalities, and using (3.2) and (3.3) we get

$$
G(x, z, z)=G(y, t, t)=0
$$

and, consequently, $(x, y)=(z, t)$.

Theorem 3.2. In addition to the hypotheses of Theorem 2.1, if $x_{0}$ and $y_{0}$ are comparable, then the coupled fixed point $(x, y) \in X \times X$ satisfies $x=y$.

Proof. Assume $x_{0} \leq y_{0}$ (a similar argument applies for $y_{0} \leq x_{0}$ ).

Then by using the mathematical induction

$$
x_{n+1}=F\left(x_{n}, y_{n}\right) \leq F\left(y_{n}, x_{n}\right)=y_{n+1} .
$$

Taking $n \rightarrow \infty$, we have

$$
x=\lim _{n \rightarrow \infty} x_{n} \leq \lim _{n \rightarrow \infty} y_{n}=y .
$$

From the contractive condition, we get

$$
\begin{aligned}
& \varphi(G(x, y, y)) \\
& =\varphi(G(F(x, y), F(y, x), F(y, x))) \\
& \leq \varphi(\max \{G(x, y, y), G(x, x, y)\})-\psi(\max \{G(x, y, y), G(x, x, y)\}) \\
& \leq \varphi(\max \{G(x, y, y), G(x, x, y)\})
\end{aligned}
$$

and

$$
\begin{aligned}
& \varphi(G(x, x, y)) \\
& =\varphi(G(F(x, y), F(x, y), F(y, x))) \\
& \leq \varphi(\max \{G(x, y, y), G(x, x, y)\})-\psi(\max \{G(x, y, y), G(x, x, y)\}) \\
& \leq \varphi(\max \{G(x, y, y), G(x, x, y)\}) .
\end{aligned}
$$

Since $\varphi:[0, \infty) \rightarrow[0, \infty)$ is nondecreasing, $\varphi(\max \{a, b\})=\max \{\varphi(a), \varphi(b)\}$ for $a, b \in[0, \infty)$. Taking into account this and the last two inequalities we get

$$
\psi(\max \{G(x, y, y), G(x, x, y)\})=0 .
$$


Using the fact that $\psi$ is nondecreasing, we have

$$
G(x, y, y)=G(x, y, y)=0
$$

and, consequently, $x=y$.

Example 3.3. Let $X=\left[0, \frac{1}{2}\right]$. Then $(X, \leq)$ is a partially ordered set with a natural ordering of real numbers. Let $G(x, y, z)=|x-y|+|y-z|+|z-x|$ for all $x, y, z \in X$. Let $F: X \times X \rightarrow X$ be defined as

$$
F(x, y)=\left\{\begin{array}{cl}
\frac{x^{2}-y^{2}+1}{3}, & x \leq y \\
\frac{1}{3}, & x>y
\end{array}\right.
$$

Then

(1) $(X, G)$ is a complete $G$-metric space;

(2) $F$ has the mixed monotone property;

(3) $F$ is continuous;

(4) $0 \leq F\left(0, \frac{1}{2}\right)$ and $\frac{1}{2} \geq F\left(\frac{1}{2}, 0\right)$;

(5) there exist two altering distance functions $\varphi$ and $\psi$ such that

$$
\begin{aligned}
& \varphi(G(F(x, y), F(u, v), F(w, z))) \\
& \leq \varphi(\max \{G(x, u, w), G(y, v, z)\})-\psi(\max \{G(x, u, w), G(y, v, z)\})
\end{aligned}
$$

for all $(x, y),(u, v),(w, z) \in X \times X$ with $x \leq u \leq w$ and $y \geq v \geq z$.

Thus by Theorem, $\mathrm{F}$ has a coupled fixed point. Moreover, $\left(\frac{1}{3}, \frac{1}{3}\right)$ is the unique coupled fixed point of $F$.

Proof. The proofs of (1)-(4) are clear.

For any $x \leq u \leq w$ and $y \geq v \geq z$, we have

$$
G(x, u, w)=2(w-x), \quad G(y, v, z)=2(y-z) .
$$

The proof of (5) is divided into the following cases.

Case 1. If $w \leq z$. In this case, we have $x \leq u \leq w \leq z \leq v \leq y$, and so

$$
F(x, y)=\frac{x^{2}-y^{2}+1}{3}, \quad F(u, v)=\frac{u^{2}-v^{2}+1}{3}, \quad F(w, z)=\frac{w^{2}-z^{2}+1}{3} .
$$

Hence, we get

$$
\begin{aligned}
G(F(x, y), F(u, v), F(w, z)) & =G\left(\frac{x^{2}-y^{2}+1}{3}, \frac{u^{2}-v^{2}+1}{3}, \frac{w^{2}-z^{2}+1}{3}\right) \\
& =\frac{2}{3}\left(y^{2}-x^{2}+w^{2}-z^{2}\right) \\
& \leq \frac{1}{3} \max \left\{2\left(y^{2}-z^{2}\right), 2\left(w^{2}-x^{2}\right)\right\} \\
& \leq \frac{1}{3} \max \{2(y-z), 2(w-x)\} .
\end{aligned}
$$


Case 2. $w>z$. We divide the study in two sub-cases:

(a) If $u \leq v$, then $x \leq u \leq v \leq y$. Therefore, we get

$$
F(x, y)=\frac{x^{2}-y^{2}+1}{3}, \quad F(u, v)=\frac{u^{2}-v^{2}+1}{3}, \quad F(w, z)=\frac{1}{3} .
$$

Hence, we get

$$
\begin{aligned}
G(F(x, y), F(u, v), F(w, z)) & =G\left(\frac{x^{2}-y^{2}+1}{3}, \frac{u^{2}-v^{2}+1}{3}, \frac{1}{3}\right) \\
& =\frac{2}{3}\left(y^{2}-x^{2}\right) \\
& \leq \frac{2}{3}\left(y^{2}-x^{2}+w^{2}-z^{2}\right) \\
& \leq \frac{1}{3} \max \left\{2\left(y^{2}-z^{2}\right), 2\left(w^{2}-x^{2}\right)\right\} \\
& \leq \frac{1}{3} \max \{2(y-z), 2(w-x)\} .
\end{aligned}
$$

(b) If $u>v$, hence $F(u, v)=\frac{1}{3}=F(w, z)$; the case where $x>y$ is obvious because we get $F(x, y)=\frac{1}{3}$. If $x \leq y$, we have $F(x, y)=\frac{x^{2}-y^{2}+1}{3}$. Therefore

$$
\begin{aligned}
G(F(x, y), F(u, v), F(w, z)) & =G\left(\frac{x^{2}-y^{2}+1}{3}, \frac{1}{3}, \frac{1}{3}\right) \\
& =\frac{2}{3}\left(y^{2}-x^{2}\right) \\
& \leq \frac{2}{3}\left(y^{2}-x^{2}+w^{2}-z^{2}\right) \\
& \leq \frac{1}{3} \max \left\{2\left(y^{2}-z^{2}\right), 2\left(w^{2}-x^{2}\right)\right\} \\
& \leq \frac{1}{3} \max \{2(y-z), 2(w-x)\} .
\end{aligned}
$$

In all the above cases, the condition (5) is satisfied for the altering distance functions $\varphi=I$ and $\psi=\frac{2}{3} I$ (where $I$ is an identity mapping). Since $X=\left[0, \frac{1}{2}\right]$ is a totally ordered set, by Theorem $3.2,\left(\frac{1}{3}, \frac{1}{3}\right)$ is the the unique coupled fixed point of $F$.

\section{References}

[1] M. Abbas, M. Ali Khan, S. Radenović, Common coupled fixed point theorems in cone metric spaces for w-compatible mappings, Appl. Math. Comput., 217 (1)(2010), 195202.

[2] M. Abbas, A. R. Khan, T. Nazir, Coupled common fixed point results in two generalized metric spaces, Appl. Math. Comput., 217(2011), 6328-6336

[3] M. Abbas, B. E. Rhoades, Common fixed point results for noncommuting mappings without continuity in generalized metric spaces, Appl. Math. Comput., 215(2009), 262-269

[4] R. P. Agarwal, M. A. El-Gebeily, D. O'Regan, Generalized contractions in partially ordered metric spaces, Appl. Anal., 87(1)(2008), 109-116.

[5] I. Altun, H. Simsek, Some fixed point theorems on ordered metric spaces and application, Fixed Point Theory Appl., (2010) Article ID 621492. 
[6] H. Aydi, B. Damjanović, B. Samet, W. Shatanawi, Coupled fixed point theorems for nonlinear contractions in partially ordered $G$-metric spaces, Math. Comput. Model., 54(2011), 2443-2450

[7] H. Aydi, M. Postolache, W. Shatanawi, Coupled fixed point results for $(\psi, \phi)$-weakly contractive mappings in ordered $G$-metric spaces. Comput. Math. Appl., 63(2012), 298-309

[8] I. Beg, A. R. Butt, Fixed point for set-valued mappings satisfying an implicit relation in partially ordered metric spaces, Nonlinear Anal., 71(2009) 3699-3704.

[9] L. Ćirić, N. Cakić, M. Rajović, J.S. Ume, Monotone generalized nonlinear contractions in partially ordered metric spaces, Fixed Point Theory Appl., (2008) Article ID 131294.

[10] B. S. Choudhury, P. Maity, Coupled fixed point results in generalized metric spaces, Math. Comput. Model., 54(2011), 73-79

[11] R. Chugh, T. Kadian, A. Rani, B.E. Rhoades, Property $P$ in G-metric spaces, Fixed Point Theory Appl. 2010, Article ID 401684

[12] T. Gnana Bhaskar and V. Lakshmikantham, Fixed point theorems in partially ordered metric spaces and applications, Nonlinear Anal., 65 (2006), 1379-1393.

[13] J. Harjani, B. López, K. Sadarangani, Fixed point theorems for mixed monotone operators and applications to integral equations, Nonlinear Anal., 74 (2011), 17491760.

[14] J. Harjani, K. Sadarangani, Generalized contractions in partially ordered metric spaces and applications to ordinary differential equations, Nonlinear Anal., 72(3-4)(2010), 1188-1197.

[15] M. S. Khan, M. Swaleh, S. Sessa, Fixed point theorems by altering distances between the points, Bull. Austral. Math. Soc., 30(1)(1984), 1-9.

[16] V. Lakshmikantham and L. Ćirić, Coupled fixed point theorems for nonlinear contractions in partially ordered metric spaces, Nonlinear Anal., 70(2009), 4341-4349.

[17] N. V. Luong, N. X. Thuan, Coupled fixed points in partially ordered metric spaces and application, Nonlinear Anal., 74(2011), 983-992.

[18] N. V. Luong, N. X. Thuan, Coupled fixed point theorems in partially ordered G-metric spaces, Math. Comput. Model., 55(2012), 1601-1609

[19] Z. Mustafa, W. Shatanawi, M. Bataineh,Fixed point theorems on incomplete G-metric spaces, J. Math. Stat., 4(2008), 196-201

[20] Z. Mustafa, W. Shatanawi, M. Bataineh, Existence of fixed point result in G-metric spaces, Int. J. Math. Math. Sci. 2009, Article ID 283028

[21] Z. Mustafa, B. Sims, A new approach to generalized metric spaces J. Nonlinear Convex Anal., 7(2)(2006), 289-297

[22] Z. Mustafa, B. Sims, Fixed point theorems for contractive mappings in complete Gmetric space, Fixed Point Theory Appl. 2009, Article ID 917175

[23] H. K. Nashine, B. Samet, J. K. Kim, Fixed point results for contractions involving generalized altering distances in ordered metric spaces, Fixed Point Theory Appl., (2011) 2011:5. 
[24] J. J. Nieto, R. Rodríguez-López, Contractive mapping theorems in partially ordered sets and applications to ordinary differential equations, Order 22(3)(2005), 223-239.

[25] D. O'Regarn, A. Petrusel, Fixed point theorems for generalized contractions in ordered metric spaces, J. Math. Anal. Appl., 341(2008), 1241-1252.

[26] A. C. M. Ran and M. C. B. Reurings, A fixed point theorem in partially ordered sets and some applications to matrix equations, Proc. Amer. Math. Soc., 132(2004), 1435-1443.

[27] R. Saadati, S. M. Vaezpour, P. Vetro, B. E. Rhoades, Fixed point theorems in generalized partially ordered G-metric spaces, Math. Comput. Model., 52(2010), 797-801

[28] W. Shatanawi, M. Abbas, H. Aydi, N. Tahat, Common coupled coincidence and coupled fixed points in G-metric spaces, J. Nonlinear Anal. Appl. 2012, Article ID jnaa-00162

[29] B. Samet, Coupled fixed point theorems for a generalized Meir-Keeler contraction in partially ordered metric spaces, Nonlinear Anal., 72(12)(2010), 4508-4517.

[30] B. Samet, C. Vetro, P. Vetro, Fixed point theorems for $\alpha-\psi$ contractive type mappings, Nonlinear Anal., 75(2012), 2154-2165. 